\title{
Applications of Direct Injection Soft Chemical Ionisation-Mass Spectrometry for the Detection of Pre-blast Smokeless Powder Organic Additives
}

\author{
Ramón González-Méndez, ${ }^{1,2}$ ๑ Chris A. Mayhew ${ }^{1,3}$ \\ ${ }^{1}$ Molecular Physics Group, School of Physics and Astronomy, University of Birmingham, Edgbaston, Birmingham, B15 2TT, UK \\ ${ }^{2}$ Centre for Agroecology, Water and Resilience, Coventry University, Coventry, CV1 5FB, UK \\ ${ }^{3}$ Institut für Atemgasanalytik, Leopold-Franzens-Universität Innsbruck, Rathausplatz 4, A-6850, Dornbirn, Austria
}

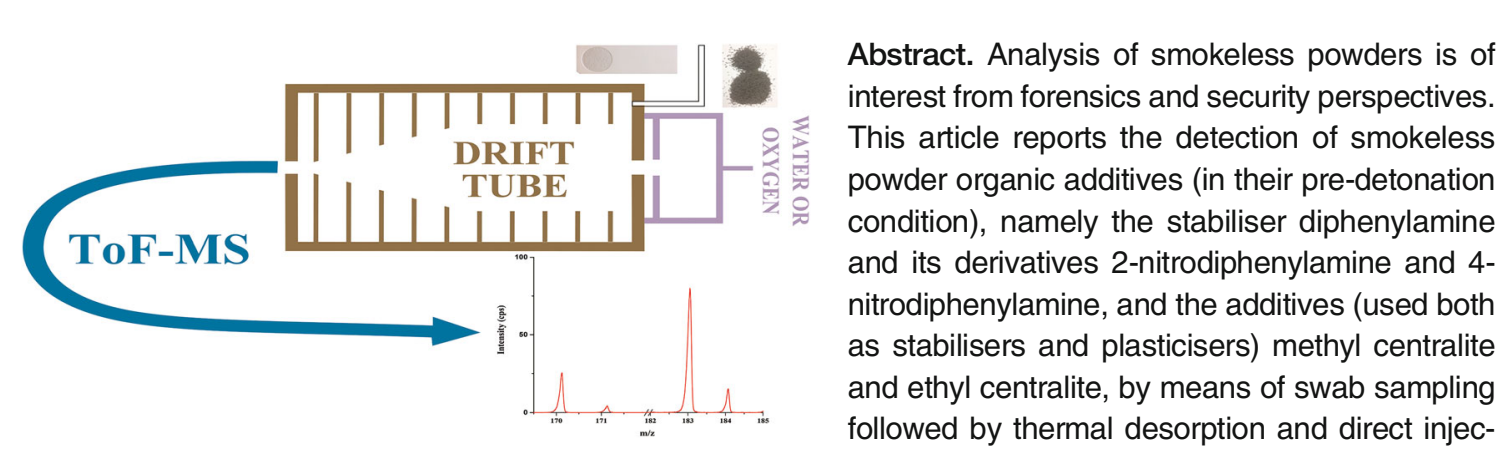

tion soft chemical ionisation-mass spectrometry. Investigations on the product ions resulting from the reactions of the reagent ions $\mathrm{H}_{3} \mathrm{O}^{+}$and $\mathrm{O}_{2}{ }^{+}$with additives as a function of reduced electric field are reported. The method was comprehensively evaluated in terms of linearity, sensitivity and precision. For $\mathrm{H}_{3} \mathrm{O}^{+}$, the limits of detection (LoD) are in the range of $41-88 \mathrm{pg}$ of additive, for which the accuracy varied between 1.5 and $3.2 \%$, precision varied between 3.7 and $7.3 \%$ and linearity showed $R^{2} \geq 0.9991$. For $\mathrm{O}_{2}{ }^{+}, \mathrm{LOD}$ are in the range of 72 to $1.4 \mathrm{ng}$, with an accuracy of between 2.8 and $4.9 \%$ and a precision between 4.5 and $8.6 \%$ and $R^{2} \geq 0.9914$. The validated methodology was applied to the analysis of commercial pre-blast gun powders from different manufacturers.

Keywords: Soft chemical ionisation-mass spectrometry, SCIMS, Proton transfer reaction mass spectrometry, PTR-MS, Smokeless powders, Smokeless powder additives

Received: 5 October 2018/Revised: 13 December 2018/Accepted: 28 December 2018/Published Online: 13 February 2019

\section{Introduction}

mokeless powders are a large and complex family of $N$ products used as propellants in ammunition cartridges [1], categorized as low explosives (they burn rapidly instead of detonating) [2]. They are commonly employed in forensic analyses as their residues can be used as evidence for firearms discharge $[3,4]$. They are also relevant from a Homeland Security perspective, as they are readily available and can be employed in the manufacturing of improvised explosive

Research Highlights • Use of direct injection soft chemical ionisation-mass spectrometry for smokeless powder organic additive analysis

Correspondence to: Ramón González-Méndez;

e-mail: R.GonzalezMendez@bham.ac.uk devices (IEDs) [5]. They exhibit a complex composition, consisting of an explosive material (nitrocellulose, nitroglycerin, nitroguanidine or different mixtures of them) [1], heavy metals $[1,6]$ and a large number of different classes of organic compounds $[1,7,8]$. The latter became of great interest after the introduction of heavy metal-free ammunition in the market [3]. Within the organic additive category, we can include plasticizers, stabilisers, opacifiers, flash suppressants, coolants, surface lubricants and dyes. [2, 9-13] The aim of these additives is to increase the shelf-life and modify the burning characteristics of the powder [5, 14]. Different concentrations and/ or different additives are characteristic of a given manufacturer, producing therefore a chemical fingerprint for each powder [15]. It is thus also important to determine their content throughout the manufacturing quality control process. Among all the possible additives, there are a number of key chemicals 
usually present and regarded as characteristic of smokeless powders $[1,12,16]$. The most common are the stabiliser diphenylamine (DPA) and its derivatives 2 nitrodiphenylamine (2- $\mathrm{NO}_{2}$-DPA) and 4-nitrodiphenylamine (4- $\mathrm{NO}_{2}$-DPA), and the additives (used both as stabilisers and plasticisers) methyl centralite (MC) and ethyl centralite (EC), which are the subject of this current paper-for structural information, see Table 1.

Several analytical techniques have been used for the qualitative and/or quantitative detection of smokeless powders, either in their pre- and/or post-blast forms [9, 10], including highperformance liquid chromatography (HPLC) [17-19], liquid chromatography-mass spectrometry (LC-MS) [8, 20-22], Fourier transform infrared spectroscopy [23], gas chromatography (GC) $[12,14,24]$, capillary electrophoresis (CE) [25, 26], ion mobility spectrometry (IMS) [27], solid-phase microextraction-ion mobility spectrometry (SPME)-IMS [12, 28], (nano)electrospray ionization (nESI)-tandem mass spectrometry [29-31], laser electrospray-mass spectrometry (LEMS) [15, 32], desorption electrospray ionization-mass spectrometry (DESI) [33, 34], direct analysis in real timemass spectrometry (DART-MS) [35], time-of-flight secondary ion-mass spectrometry (ToF-MS) [36] and Raman spectroscopy $[23,37]$. Most of the abovementioned techniques require time-consuming sample preparation step(s) - exception of DESI and DART - or if not, they require complicated setups, such as the use of lasers as the means for sample vaporization (LEMS) or heated purified gases (DART). Here is where direct injection (DI) soft chemical ionisation-mass spectrometry (SCIMS) can compete (and/or be complementary) with these techniques for rapid, selective and sensitive detection of chemical compounds in complex environments. DI-SCIMS is an analytical technique for mass spectrometric gas analysis based on the ionization of neutrals by ion/molecule reactions with a reagent ion (such as $\mathrm{H}_{3} \mathrm{O}^{+}, \mathrm{O}_{2}{ }^{+}$or $\mathrm{NO}^{+}$). This occurs within the controlled environment of a drift tube (DT) under the effect of an electric field $E$. The resulting ionised analyte molecules are then mass analysed by mass spectrometer. It is a direct injection technique as samples are injected directly into the drift tube of the instrument.

There are several analytical techniques that belong to the DI-SCIMS category $[38,39]$, with proton transfer reactionmass spectrometry (PTR-MS) arguably the most widespread. PTR-MS was purposely designed for the monitoring of volatile organic compounds (VOCs) [40], but has developed further to analyse liquid and solid compounds [38], being successfully applied to the detection of explosives and explosive-related compounds in positive-ion mode [41-50]. Technically speaking, PTR-MS only refers to the use of hydronium as the reagent ion. Given that in this study we investigated reactions involving $\mathrm{O}_{2}{ }^{+}$and $\mathrm{H}_{3} \mathrm{O}^{+}$, the term SCIMS is a more accurate description of the instrument for this work.

In this paper, we report the first DI-SCIMS studies of the additives to smokeless powders, namely DPA, 2- $\mathrm{NO}_{2}$-DPA, 4$\mathrm{NO}_{2}$-DPA, MC and EC, using $\mathrm{H}_{3} \mathrm{O}^{+}$and $\mathrm{O}_{2}{ }^{+}$as the reagent ions. We can expect efficient reactions with $\mathrm{H}_{3} \mathrm{O}^{+}$because the

Table 1. Molecular Weight, Linear Formula and Chemical Structure for the Components Investigated

\begin{tabular}{|c|c|c|c|}
\hline Additive & $\begin{array}{c}\text { Molar weight, } \\
\text { g mol-1 }\end{array}$ & Linear formula & $\begin{array}{l}\text { Chemical } \\
\text { structure }\end{array}$ \\
\hline Diphenylamine (DPA) & 169.22 & $\left(\mathrm{C}_{6} \mathrm{H}_{5}\right)_{2} \mathrm{NH}$ & \\
\hline $\begin{array}{l}\text { 2-nitrodiphenylamine } \\
\left(2-\mathrm{NO}_{2}-\mathrm{DPA}\right)\end{array}$ & 214.22 & $\mathrm{C}_{6} \mathrm{H}_{5} \mathrm{NHC}_{6} \mathrm{H}_{4} \mathrm{NO}_{2}$ & \\
\hline $\begin{array}{l}\text { 4-nitrodiphenylamine } \\
\left(4-\mathrm{NO}_{2}-\mathrm{DPA}\right)\end{array}$ & 214.22 & $\mathrm{C}_{6} \mathrm{H}_{5} \mathrm{NHC}_{6} \mathrm{H}_{4} \mathrm{NO}_{2}$ & \\
\hline Methyl centralite (MC) & 240.30 & {$\left[\mathrm{C}_{6} \mathrm{H}_{5} \mathrm{~N}\left(\mathrm{CH}_{3}\right)\right]_{2} \mathrm{CO}$} & $\mathrm{CH}_{3}$ \\
\hline Ethylcentralite (EC) & 268.35 & {$\left[\mathrm{C}_{6} \mathrm{H}_{5} \mathrm{~N}\left(\mathrm{C}_{2} \mathrm{H}_{5}\right)\right]_{2} \mathrm{CO}$} & \\
\hline
\end{tabular}


proton affinities for amine and amide-based compounds are higher than that of water. Certain studies involving ESI-MS [31] and IMS [51] show that these neutrals can be detected with a high sensitivity. Based on the identified ions, analytical figures of merit (limits of detection, linear dynamic range, repeatability and reproducibility) are established. This information should help in the development of a highly selective analytical technique for smokeless powder organic additive detection using DI-SCIMS.

\section{Experimental Details}

\section{Proton Transfer Reaction Mass Spectrometry}

A Kore Technology Ltd. Series I PTR-ToF-MS instrument was used. Details of using PTR-MS are given in detail elsewhere $[38,47]$, and therefore, only pertinent issues will be briefly mentioned here. Recently, this instrument was equipped with a radiofrequency ion funnel drift tube and fast reaction region reduced electric field, E/N, switching capabilities [50]. However, for these studies, the RF operation was not used.

Fast Reduced Electric Field Switching Details of the fast switching have been given elsewhere [50]. In brief, this new hardware development feature allows the rapid switching of the reduced electric field with transition times less than $140 \mathrm{~ms}$ $(0.1-5 \mathrm{~Hz})$ within the reaction region. This alters the reagent ion composition and ion molecule collisional energies, leading to differences in product ions between the two operational $E / N$ values. This new hardware development allows for the manipulation of the ion chemistry, modifying the product ion distribution to provide more information to aid in assignment of the neutral responsible for the observed product ion(s).

$\mathrm{H}_{3} \mathrm{O}^{+}$Production Water vapour is introduced into a hollow cathode glow discharge where, after ionisation via electron impact and subsequent ion molecule processes, the terminal reagent ion is $\mathrm{H}_{3} \mathrm{O}^{+}$. These ions are transferred from the ion source into the drift tube by an applied voltage gradient where they react with the analyte $\mathrm{M}$ by donating their protons at the collisional rate; providing $\mathrm{M}$ has a proton affinity greater than that of water $\left(\mathrm{PA}\left(\mathrm{H}_{2} \mathrm{O}\right)=691 \mathrm{~kJ} \mathrm{~mol}^{-1}\right)$. This process can be either non-dissociative (resulting in the protonated molecule $\mathrm{MH}^{+}$) and/or dissociative. Dissociative proton transfer results in product ions, which depend on their $\mathrm{m} / \mathrm{z}$ values, may be useful for the identification of a compound. Fragmentation may be spontaneous upon proton transfer or may require additional energy which is supplied through collisions with the buffer gas resulting during the migration of ions under the influence of the electric field, $E$. Ions are separated using a time-of-flight mass analyser and detected by means of a multichannel plate. $\mathrm{O}_{2}{ }^{+}$is also formed as an impurity due to air back flow from the reactor into the ion source region [43]; however, the instrument was operated in a manner that this was below $2 \%$ of the $\mathrm{H}_{3} \mathrm{O}^{+}$signal intensity.
$\mathrm{O}_{2}{ }^{+}$Production For the production of $\mathrm{O}_{2}{ }^{+}$, water vapour in the discharge is replaced by pure oxygen $(99.998 \%$ purity, BOC Gases, Manchester, UK). This leads to the formation of mainly $\mathrm{O}_{2}^{+}$reagent ions (>95\%) [52]. Once injected into the DT, $\mathrm{O}_{2}{ }^{+}$reacts with the analyte $\mathrm{M}$ via charge transfer, provided that the ionisation potential of $\mathrm{M}$ is less than that of $\mathrm{O}_{2}$ [53]. Similarly to 2.1.2, this reaction may be non-dissociative and/or dissociative, and fragmentation may be spontaneous upon charge transfer or require additional energy. $\mathrm{H}_{3} \mathrm{O}^{+}$is also observed due to residual water vapour in the system, with signal intensity below around $2.5 \%$ of the $\mathrm{O}_{2}{ }^{+}$signal for the experimental conditions used throughout.

It is worth to highlight that when using $\mathrm{O}_{2}{ }^{+}$as the reagent ion, it is possible to start measurements at lower $E / N$ values than when using $\mathrm{H}_{3} \mathrm{O}^{+}$. This is a consequence of the lack of water clustering for $\mathrm{O}_{2}^{+}$. This reagent ion signal had to be inferred from its corresponding isotopologue ${ }^{16} \mathrm{O}^{18} \mathrm{O}$ at $\mathrm{m} / \mathrm{z}$ 33.99 , owing to detection saturation at $m / z 31.99$.

\section{Operational Parameters}

A thermal desorption unit (TDU) connected to the inlet of the drift tube through passivated (Silconert ${ }^{\circledR}$ ) stainless steel (10$\mathrm{cm}$ length) was used to introduce the samples. Details of the TDU have been given elsewhere [41]. The TDU, connecting lines and drift tube were operated at a temperature of $150{ }^{\circ} \mathrm{C}$ (maximum possible temperature). PTFE swabs (ThermoFisher Scientific, Cheshire, UK) onto which known quantities of additives were deposited were placed into the TDU. For this study, laboratory air was used as the carrier gas. Prior to making contact with the swab, the carrier gas was passed through an oxygen/moisture trap (Agilent OT3-4) - not used for $\mathrm{O}_{2}^{+}$mode - and hydrocarbon trap (Agilent HT200-4). Upon closure of the TDU, a seal is created, and the carrier gas is heated to the temperature of the TDU before it flows through a series of apertures in the heated metal plate. This heated air then passes through the swab and into the inlet system driving any desorbed material through to the drift tube creating a temporal concentration "pulse" of typically between 10 and $20 \mathrm{~s}$ of an analyte in the drift tube [41]. For the product ion distribution and branching ratio studies, each swab provided one measurement, which was replicated three times, and then, the results were averaged, and any background signals were subtracted.

The drift tube was maintained at a pressure of $1.1 \mathrm{mbar}$, and the glow discharge (for both water vapour and oxygen) was set at 1.3 mbar (which is a combination of the reagent neutral pressure and air back flowing from the drift tube).

For the fast switching experiments, the acquisition time per point was set to $40 \mathrm{~ms}$ and ion signals were averaged for each individual cycle.

In the following, only product ions with a product ion distribution (PID) greater than $1 \%$ are reported and the $\mathrm{m} / \mathrm{z}$ of the lightest isotopologue will be given. However, when calculating the product ion distributions, all of the isotopologues are taken into account. 


\section{Chemical Standards and Smokeless Powder Samples}

Table 1 gives details of the molar mass and structure of the five compounds investigated in this study.

These chemicals were individually purchased from AccuStandard Inc. (New Haven, CT, USA) and used without additional treatment. DPA is dissolved in $\mathrm{MeOH}$; $\mathrm{MC}$ and $\mathrm{EC}$ are prepared in a mixture of $\mathrm{MeOH} / \mathrm{AcN} 1: 1(v / v)$ and 2- and 4$\mathrm{NO}_{2}$-DPA in AcN. Concentrations in all cases were $100 \mu \mathrm{g} \mathrm{mL}$ ${ }^{-1}$. Further dilutions of this mother solutions in the appropriate solvent(s) (HPLC grade) were prepared when needed. Typically, $1 \mu \mathrm{L}$ of a solution of the required concentration was spotted onto the swab and left to evaporate the solvents for $1 \mathrm{~min}$ prior to insertion into the TDU.

Smokeless powders (either used for guns or rifles) were acquired in a local ammunition wholesaler. Rifle powders are typically single based (the only energetic material is nitrocellulose), and gun powders are double based (nitrocellulose together with nitroglycerine). When needed, $1 \mathrm{~g}$ of powder was dissolved in $10 \mathrm{~mL}$ of dichloromethane (HPLC grade) for $10 \mathrm{~min}$ at room temperature with the help of an ultrasonic bath. Once the solvent evaporated at room temperature, the residue was dissolved in $100 \mathrm{~mL}$ of a mixture of $\mathrm{MeOH} /$ acetonitrile 1:1 $(v / v)$. Again, $1 \mu \mathrm{L}$ was spotted onto the swab and left solvents to evaporate for $1 \mathrm{~min}$ prior to insertion into the TDU.

\section{Results and Discussion}

\section{Analysis of Standard Additives, Fragmentation Patterns and Branching Ratio Studies in $\mathrm{H}_{3} \mathrm{O}^{+}$ and $\mathrm{O}_{2}^{+}$Modes}

Diphenylamine In $\mathrm{H}_{3} \mathrm{O}^{+}$mode (data not shown), the protonated parent [DPA.H $]^{+}$at a $\mathrm{m} / z$ of 170.10 dominates across the $E / N$ range studied (80-200 Td). One other product ion is observed at high $E / N$ values (180 Td and above) at $\mathrm{m} / z$ 92.05. This is assigned to $\left[\mathrm{C}_{6} \mathrm{H}_{5} \mathrm{NH}\right]^{+}$, resulting from the loss of benzene from the protonated parent, increasing its intensity from negligible at low $E / N$ to a maximum of $5 \%$ at $200 \mathrm{Td}$.

In $\mathrm{O}_{2}{ }^{+}$mode (data not shown), only $\mathrm{DPA}^{+}$at $m / z$ 169.09, resulting from non-dissociative charge transfer, is observed for all the $E / N$ values (60-200 Td).

2-Nitrodiphenylamine (2- $\left.\mathrm{NO}_{2}-\mathrm{DPA}\right)$ and 4Nitrodiphenylamine (4- $\left.\mathrm{NO}_{2}-\mathrm{DPA}\right)$ Figure 1 shows the PID plots for (a) 2- $\mathrm{NO}_{2}$-DPA and (b) 4- $\mathrm{NO}_{2}-\mathrm{DPA}$ for their reaction with $\mathrm{H}_{3} \mathrm{O}^{+}$as a function of $E / N$ (for the range from 80 to 200 Td). For both chemicals, the fragmentation pattern is very similar, and only differences ascribe to the ortho effect (amine and nitro groups in adjacent positions for 2- $\mathrm{NO}_{2}-\mathrm{DPA}$ ) are observed. For both isomers, the protonated parent, $\mathrm{m} / \mathrm{z}$ 215.08 , is the dominant ion, with the exception of the 2isomer at $E / N$ values above $190 \mathrm{Td}$, where a product ion at $m / z 197.07$ (loss of $\mathrm{H}_{2} \mathrm{O}$ ) takes over. For the 4-isomer, a loss of a hydroxyl group, giving a product ion at $m / z 198.08$, is also observed. This is consistent with the ortho observed behaviour, where $\left[\mathrm{M}-\mathrm{OH}_{2}\right] \mathrm{H}^{+}$replaces the $[\mathrm{M}-\mathrm{OH}] \mathrm{H}^{+}$fragment ion $[47$, 54]. For the 2-isomer, a subsequent loss of an hydroxyl group (only observed at $E / N>160 \mathrm{Td}$ ) leads to the product ion at $\mathrm{m} / \mathrm{z}$ 180.06 , the intensity of which increases as the $E / N$ increases. Finally, another product ion at $\mathrm{m} / \mathrm{z} 169.07$ corresponding to the nitro group loss from the protonated parent is observed in both isomers with different intensities (maximum values of ca. $8.5 \%$ for 2 -isomer and ca. $14 \%$ for the 4 -isomer, at $200 \mathrm{Td}$ ), and becoming relevant only above $150 \mathrm{Td}$ in both cases.

In $\mathrm{O}_{2}{ }^{+}$mode (PID plot not shown) and for both 2- and 4$\mathrm{NO}_{2}$-DPA, the parent ion at $\mathrm{m} / \mathrm{z} 214.07$, the result of nondissociative reaction channel, dominates. Its intensity decreases as the reduced electric field increases, dropping down to $25 \%$ at $180 \mathrm{Td}$ of the initial intensity at $80 \mathrm{Td}$. Other fragment ion, at $\mathrm{m} / \mathrm{z} 163.22$ (unassigned in this paper), is observed in both cases, the intensity of which slightly decreases as the reduced electric field increases (from $\sim 2 \%$ at $60 \mathrm{Td}$ to $3.5 \%$ at $200 \mathrm{Td}$ for $2-\mathrm{NO}_{2}$-DPA and from $\sim 3.5$ to $7 \%$ for $4-\mathrm{NO}_{2}$-DPA). This unidentified ion is consistent with the observations reported by Perez et al. [32]

Methyl Centralite In $\mathrm{H}_{3} \mathrm{O}^{+}$mode, the protonated parent at $m / z 241.13$, [MC.H] $]^{+}$, is observed as the dominant ion up to around $190 \mathrm{Td}$ (Fig. 2a). Other observed product ions are $\mathrm{m} / \mathrm{z}$ 134.06, assigned to $\left[\mathrm{PhNCH}_{3} \mathrm{CO}\right]^{+}$(resulting from the loss of $\mathrm{N}$-methylaniline from the protonated parent), and $\mathrm{m} / \mathrm{z} 106.07$ (a subsequent loss of a $\mathrm{CO}$ molecule leaving a $\left[\mathrm{PhNCH}_{3}\right]^{+}$ion), which only yields a significant intensity above $140 \mathrm{Td}$ and becomes dominant above $190 \mathrm{Td}$.

In $\mathrm{O}_{2}{ }^{+}$mode (PID shown in Fig. 2b), non-dissociative charge transfer results in an ion at $\mathrm{m} / \mathrm{z} 240.12,[\mathrm{MC}]^{+}$, that dominates. Only at very high $E / N$ values, > ca. $200 \mathrm{Td}$, the ion at $\mathrm{m} / z 106.10$ becomes dominant. Additional observed product ions are $\mathrm{m} / \mathrm{z} 225.10$ (loss of a $\mathrm{CH}_{3}$ group) and $\mathrm{m} / \mathrm{z} 183.01$ (not assigned in this paper and being relevant only after $170 \mathrm{Td}$ ).

Ethyl Centralite EC has a very similar structure to that of $\mathrm{MC}$, so a similar fragmentation pattern is to be expected. For water chemistry, the protonated parent, [EC.H] $]^{+}$, at $m / z 269.17$, is dominant across all the $E / N$ range (Fig. 3a). Observed fragment product ions are $m / z 148.08$ (via loss of $N$ ethylaniline from the protonated parent) and at $\mathrm{m} / \mathrm{z} 120.08$ (loss of (O), which only becomes relevant above $120 \mathrm{Td}$. Two more product ions are observed at $\mathrm{m} / \mathrm{z}$ 93.06, assigned to be charged aniline $\left[\mathrm{PhNH}_{2}\right]^{+}$, after the additional loss of a $\mathrm{CH}_{2} \mathrm{CH}$ molecule, and $\mathrm{m} / \mathrm{z}$ 92.05, $[\mathrm{PhNH}]^{+}$, only becoming relevant at $E / N>140 \mathrm{Td}$. That these two ions are only and simultaneously observed for EC is consistent with results shown by GilbertLópez et al. in a LC/ESI-ToF-MS. [55]

For oxygen chemistry, PID shown in Fig. 3b, the ion resulting from charge transfer at $m / z$ 268.16, dominates, and only at reduced electric field values above $200 \mathrm{Td}$ loses its dominance. Identified product ions are to the same as those for 


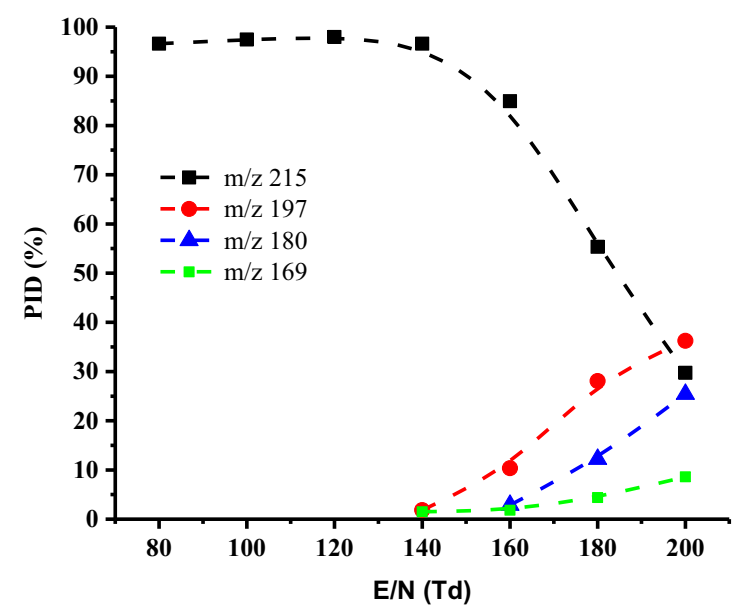

(a)

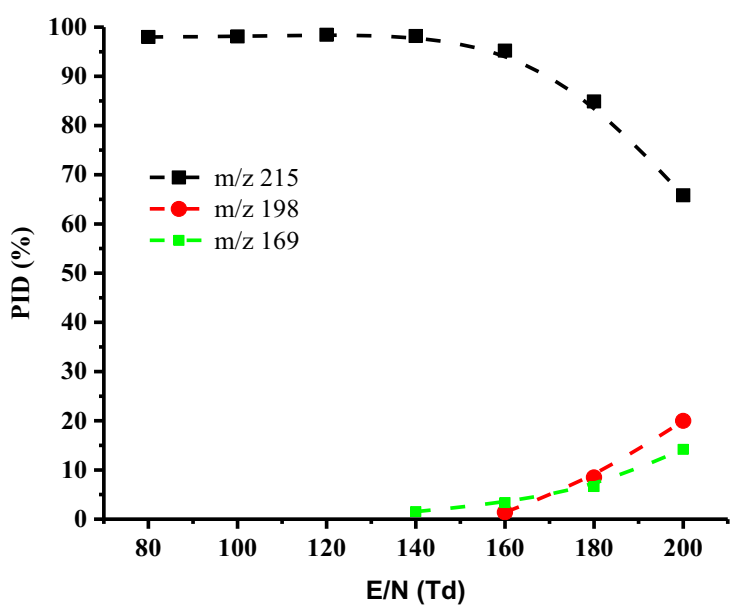

(b)

Figure 1. PID plots resulting from the reaction of $\mathrm{H}_{3} \mathrm{O}^{+}$with (a) $2-\mathrm{NO}_{2}-\mathrm{DPA}$ and (b) $4-\mathrm{NO}_{2}-\mathrm{DPA}$ as a function of reduced electric field (80 to $200 \mathrm{Td}$ )

water chemistry, namely $\mathrm{m} / \mathrm{z} 148.08,120.08,93.06$ and 92.05 , but in addition, another product ion at $m / z 164.00$ is also observed, the intensity of which remains almost constant for the range 60 to $140 \mathrm{Td}$, after which its intensity decreases to ca. $5 \%$ at $220 \mathrm{Td}$.

\section{Method Validation and Analytical Figures of Merit}

Following the establishment of the product ions, the performance of the method was evaluated in terms of limits of detection (LoD), linear dynamic range and precision for both $\mathrm{H}_{3} \mathrm{O}^{+}$and $\mathrm{O}_{2}^{+}$reagent ions (see Table 2). Serial calibration solutions of different concentrations for each standard additive were prepared. Calibration curves, using peak areas normalised to $1 \mathrm{E} 6$ reagent ions, as function of concentration using least square linear regression analysis were plotted. Instrumental LoDs were evaluated based on the minimum analyte concentration yielding to a signal-to-noise ratio equal to 3 . Noise was defined as the average of 10 blank samples for a given mass. Although the conjunction of protonated parent and fragment ions is useful for selectivity purposes, to determine the sensitivity of the method, only the dominant ion resulting in the best LoD was used, i.e. the most intense ion signal (in terms of ncps) at a given $E / N$ value was used to determine the LoD. Precision of the method was determined in terms of repeatability (measurements of five replicates within short intervals of time (typically 1-5 $\mathrm{min}$ ) by the same operator under the same experimental conditions) and reproducibility (five replicates over five different days by the same operator under the same experimental conditions), with each replicate being the mean of three measurements. Linearity was studied covering a concentration range from 0.1 to $1500 \mathrm{ng}$ of each compound at ten concentration values with three replicates at each concentration. No carryover effects were observed, and under the experimental conditions after ca. $10 \mathrm{~s}$, the baseline was recovered for

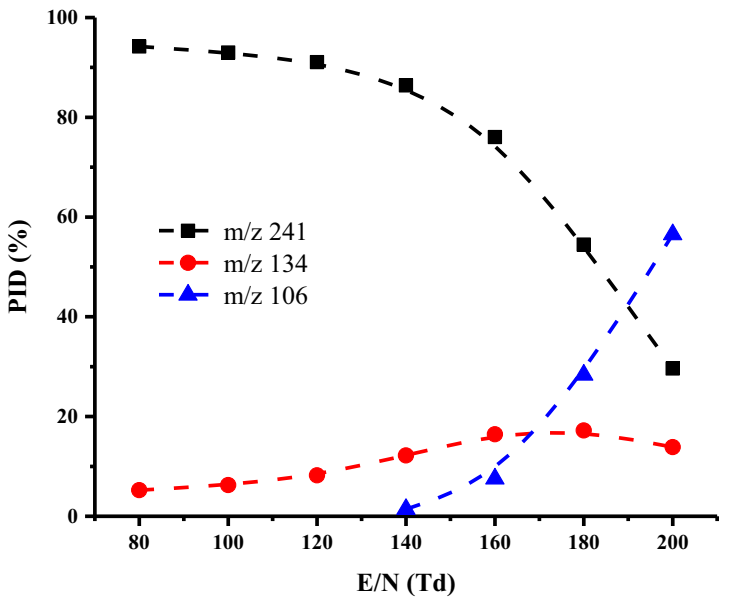

(a)

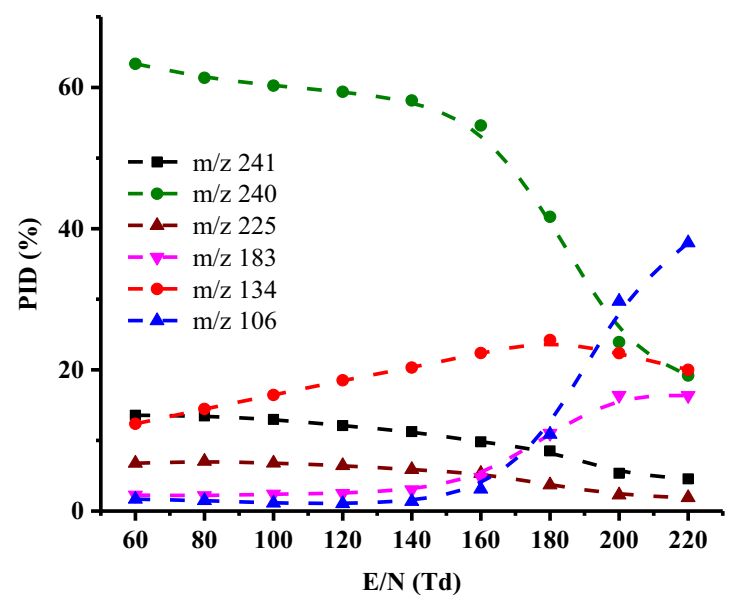

(b)

Figure 2. PID plots resulting from the reaction of $\mathrm{MC}$ with (a) $\mathrm{H}_{3} \mathrm{O}^{+}$reagent ion (80 to $\left.200 \mathrm{Td}\right)$ and (b) $\mathrm{O}_{2}{ }^{+}$reagent ion (60 to $220 \mathrm{Td}$ ) as a function of reduced electric field 


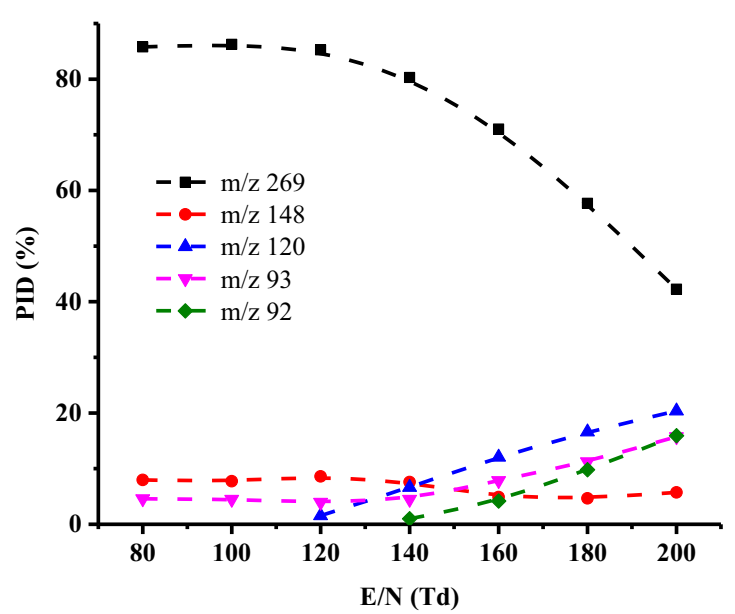

(a)

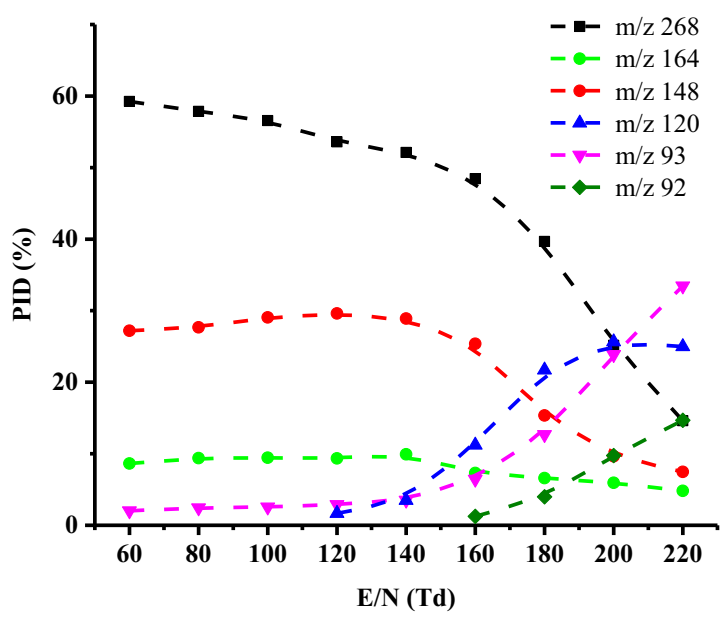

(b)

Figure 3. PID plots resulting from the reaction of $\mathrm{EC}$ with (a) $\mathrm{H}_{3} \mathrm{O}^{+}$reagent ion ( 80 to $200 \mathrm{Td}$ ) and (b) $\mathrm{O}_{2}{ }^{+}$reagent ion (60 to $220 \mathrm{Td}$ ) as a function of reduced electric field

all the compounds of interest. Thirty-second integration time was used throughout in order to record a stable background prior and after a desorption event.

In $\mathrm{H}_{3} \mathrm{O}^{+}$mode, the coefficient of determination $R^{2}$ was higher than 0.9991 for all compounds. Instrumental limits of detection varied from 41 to $88 \mathrm{pg}$. Precision, expressed in terms of relative standard deviation (RSD), was found in all cases to be below around 3\% for intra-day (repeatability) and below 7\% for inter-day (reproducibility) studies.

In $\mathrm{O}_{2}{ }^{+}$mode, the coefficient of determination $R^{2}$ was higher than 0.9914 for all compounds. Instrumental limits of detection varied from 72 to $1.4 \mathrm{ng}$. Special mention should be noted to the cases of DPA, where the existence of an endogenous high background signal at the $\mathrm{m} / \mathrm{z}$ of interest led to a LoD much higher than that of the rest of compounds, but still in the low nanogram region. Precision was found in all cases to be below around $5 \%$ for intra-day (repeatability) and below $8.6 \%$ for inter-day (reproducibility) studies.

\section{Application to Commercial Samples}

Six commercial smokeless powder samples from three different manufacturers were analysed. The concentration of additives was calculated using the standard calibration curves obtained for "Method Validation and Analytical Figures of Merit" section. Results, see Table 3, show the identified additives and its content in the smokeless gun powder (expressed as percentage) for the different samples for $\mathrm{H}_{3} \mathrm{O}^{+}$and $\mathrm{O}_{2}{ }^{+}$reagent ions at $140 \mathrm{Td}$ (a compromise $E / N$ value between high signal intensity and low fragmentation). These results are in good agreement with those found in the smokeless powder database [56]. Figure 4 shows two mass spectra exemplifying two of the samples for water chemistry - similar plots (not shown) were found for the rest of the samples and for oxygen chemistry.

Based on our previous water chemistry work $[41,47,50]$, and besides the detection of the additives studied for this work, dinitrotoluene was also clearly observed showing two

Table 2. Figures of Merit for the Compounds Investigated in This Study Using $\mathrm{H}_{3} \mathrm{O}^{+}$and $\mathrm{O}_{2}{ }^{+}$Chemistry

\begin{tabular}{|c|c|c|c|c|c|c|c|c|}
\hline \multirow[t]{2}{*}{ Compound } & \multirow[t]{2}{*}{ Reagent ion } & \multirow[t]{2}{*}{ Monitored ion, $m / z$} & \multirow[t]{2}{*}{$E / N(\mathrm{Td})$} & \multirow[t]{2}{*}{ Linear dynamic range (ng) } & \multirow[t]{2}{*}{$R^{2}$} & \multirow[t]{2}{*}{ LoD (pg) } & \multicolumn{2}{|l|}{ Precision (RSD, \%) } \\
\hline & & & & & & & $\begin{array}{l}\text { Repeatability }(n=5) \\
300 \mathrm{pg}\end{array}$ & $\begin{array}{l}\text { Reproducibility }(n=5) \\
300 \mathrm{pg}\end{array}$ \\
\hline \multirow[t]{2}{*}{ DPA } & $\mathrm{H}_{3} \mathrm{O}^{+}$ & {$[\mathrm{DPA} . \mathrm{H}]^{+}, 170.10$} & 140 & $0.15-1500$ & 0.9991 & $72 \pm 6$ & 2.9 & 5.1 \\
\hline & $\mathrm{O}_{2}^{+}$ & {$[\mathrm{DPA}]^{+}, 169.09$} & 110 & & 0.9914 & $1.4 \pm 0.1^{*}$ & 4.9 & 8.6 \\
\hline \multirow[t]{2}{*}{$2-\mathrm{NO}_{2}-\mathrm{DPA}$} & $\mathrm{H}_{3} \mathrm{O}^{+}$ & {$\left[2-\mathrm{NO}_{2}-\mathrm{DPA} \mathrm{H}\right]^{+}, 215.08$} & 140 & $0.1-1500$ & 0.9998 & $41 \pm 2$ & 2.4 & 5.2 \\
\hline & $\mathrm{O}_{2}^{+}$ & {$\left[2-\mathrm{NO}_{2}-\mathrm{DPA}\right]^{+}, 214.07$} & 80 & & 0.9954 & $72 \pm 5$ & 3.1 & 6.1 \\
\hline \multirow{2}{*}{$4-\mathrm{NO}_{2}-\mathrm{DPA}$} & $\mathrm{H}_{3} \mathrm{O}^{+}$ & {$\left[4-\mathrm{NO}_{2}-\mathrm{DPA} \mathrm{H}\right]^{+}, 215.08$} & 140 & $0.1-1500$ & 0.9996 & $51 \pm 5$ & 1.5 & 4.0 \\
\hline & $\mathrm{O}_{2}^{+}$ & {$\left[2-\mathrm{NO}_{2}-\mathrm{DPA}\right]^{+}, 214.07$} & 80 & & 0.9941 & $83 \pm 2$ & 2.8 & 4.5 \\
\hline \multirow[t]{2}{*}{$\mathrm{MC}$} & $\mathrm{H}_{3} \mathrm{O}^{+}$ & {$[\mathrm{MC} . \mathrm{H}]^{+}, 241.13$} & 130 & $0.2-1500$ & 0.9997 & $88 \pm 4$ & 2.1 & 3.7 \\
\hline & $\mathrm{O}_{2}^{+}$ & $\mathrm{MC}^{+}, 240.12$ & 60 & & 0.9965 & $310 \pm 9$ & 3.2 & 5.1 \\
\hline \multirow{2}{*}{$\mathrm{EC}$} & $\mathrm{H}_{3} \mathrm{O}^{+}$ & {$[\mathrm{EC} . \mathrm{H}]^{+}, 269.17$} & 140 & $0.15-1500$ & 0.9995 & $60 \pm 7$ & 2.2 & 4.1 \\
\hline & $\mathrm{O}_{2}^{+}$ & $\mathrm{EC}^{+}, 268.16$ & 80 & & 0.9955 & $287 \pm 6$ & 3.8 & 6.3 \\
\hline
\end{tabular}

Normalised counts per second for one million reagent ions have been used throughout. Only the dominant ion was used, and LoDs were calculated at the $E / N$ value that gave us the best sensitivity. The linear dynamic range in nanograms is given for each explosive and the corresponding $R^{2}$ provided. The precision of the method was evaluated by the determination of the repeatability and reproducibility in terms of percentage of relative standard deviation (\% RSD) of peak areas

*Expressed in nanograms. As a result of an endogenous background signal at the mass of interest, sensitivity was compromised 
Table 3. Smokeless Powder Analysis in $\mathrm{H}_{3} \mathrm{O}^{+}$and $\mathrm{O}_{2}{ }^{+}$Modes at $140 \mathrm{Td}$, Showing the Detected (or Undetected) Additives for Six Different Samples from Three Different Manufacturers

\begin{tabular}{|c|c|c|c|c|c|c|c|c|c|}
\hline & & Reagent ion & DPA & $2-\mathrm{NO}_{2}-\mathrm{DPA}$ & $4-\mathrm{NO}_{2}-\mathrm{DPA}$ & MC & $\mathrm{EC}$ & 2,4-DNT & NG \\
\hline \multirow[t]{12}{*}{ Smokeless powder manufacturer and model } & \multirow[t]{2}{*}{ Alliant Unique } & $\mathrm{H}_{3} \mathrm{O}^{+}$ & $2.0 \pm 0.25$ & $1.1 \pm 0.2$ & ND & ND & $1.2 \pm 0.1$ & ND & $\mathfrak{a}^{\mathrm{a}}$ \\
\hline & & $\mathrm{O}_{2}^{+}$ & $1.6 \pm 0.4$ & $0.9 \pm 0.3$ & ND & ND & $1.0 \pm 0.3$ & $-{ }^{\mathrm{b}}$ & - \\
\hline & \multirow[t]{2}{*}{ Alliant Red Dot } & $\mathrm{H}_{3} \mathrm{O}^{+}$ & $2.3 \pm 0.2$ & $1.4 \pm 0.3$ & ND & ND & $1.1 \pm 0.2$ & ND & $\checkmark$ \\
\hline & & $\mathrm{O}_{2}^{+}$ & $2.1 \pm 0.3$ & $1.0 \pm 0.2$ & ND & ND & $0.9 \pm 0.2$ & - & - \\
\hline & \multirow[t]{2}{*}{ Hodgdon BL-C(2) } & $\mathrm{H}_{3} \mathrm{O}^{+}$ & $1.1 \pm 0.1$ & $0.6 \pm 0.1$ & ND & ND & $3.0 \pm$ & ND & $\checkmark$ \\
\hline & & $\mathrm{O}_{2}^{+}$ & $0.9 \pm 0.1$ & ND & ND & ND & $2.7 \pm$ & - & - \\
\hline & \multirow[t]{2}{*}{ Hodgdon $\mathrm{H} 322$} & $\mathrm{H}_{3} \mathrm{O}^{+}$ & $1.6 \pm 0.6$ & $0.4 \pm 0.2$ & ND & $2.0 \pm 0.2$ & ND & $\checkmark$ & ND \\
\hline & & $\mathrm{O}_{2}^{+}$ & $1.3 \pm 0.4$ & ND & ND & $1.6 \pm 0.3$ & ND & - & - \\
\hline & \multirow[t]{2}{*}{ IMR 4350} & $\mathrm{H}_{3} \mathrm{O}^{+}$ & $4.1 \pm 0.3$ & $0.4 \pm 0.1$ & $0.6 \pm 0.2$ & $2.1 \pm 0.3$ & $1.2 \pm 0.1$ & $\checkmark$ & ND \\
\hline & & $\mathrm{O}_{2}^{+}$ & $4.0 \pm 0.5$ & $0.4 \pm 0.2$ & $0.4 \pm 0.1$ & $1.9 \pm 0.2$ & $1.0 \pm 0.3$ & - & - \\
\hline & \multirow[t]{2}{*}{ IMR 4198} & $\mathrm{H}_{3} \mathrm{O}^{+}$ & $5.0 \pm 0.1$ & ND & ND & ND & ND & $\checkmark$ & ND \\
\hline & & $\mathrm{O}_{2}^{+}$ & $4.7 \pm 0.3$ & ND & ND & ND & ND & - & - \\
\hline
\end{tabular}

Numbers indicate the content of additive in the powder (in $\%$, mean of $n=5$ ) and its error (expressed as RSD)

$N D$ not detected

$\stackrel{\checkmark}{ }$ indicates observed and identified but not quantified

b - indicates not experimentally tested for

intense product ion peaks at $m / z 183.04$ and 201.05, assigned to the protonated parent, DNT. $\mathrm{H}^{+}$, and its first water cluster, $\mathrm{DNTH}^{+} \cdot \mathrm{H}_{2} \mathrm{O}$. This was observed for three of the samples. It is possible to assign dinitrotoluene to be the 2,4-isomer. As reported recently by González-Méndez et al, [47, 50] monitoring product ions at $\mathrm{m} / \mathrm{z} 183.04$ and 201.05 allow assignment to 2,4-DNT, but that the presence of $m / z 136.04$ (elimination of HONO from the protonated parent) and $\mathrm{m} / \mathrm{z} 91.06$ (elimination of two nitro groups) observed at the high $E / N$ setting (200 $\mathrm{Td}$ and above) indicates the presence of 2,6DNT. These two latter peaks were not observed. No detailed product ion distribution studies for DNT and $\mathrm{O}_{2}{ }^{+}$exist (to the best of our knowledge), but in $\mathrm{O}_{2}{ }^{+}$mode, the charge transfer reaction channel leading to a peak at $\mathrm{m} / z 182.03$ (assigned to $[\mathrm{DNT}]^{+}$) was observed.

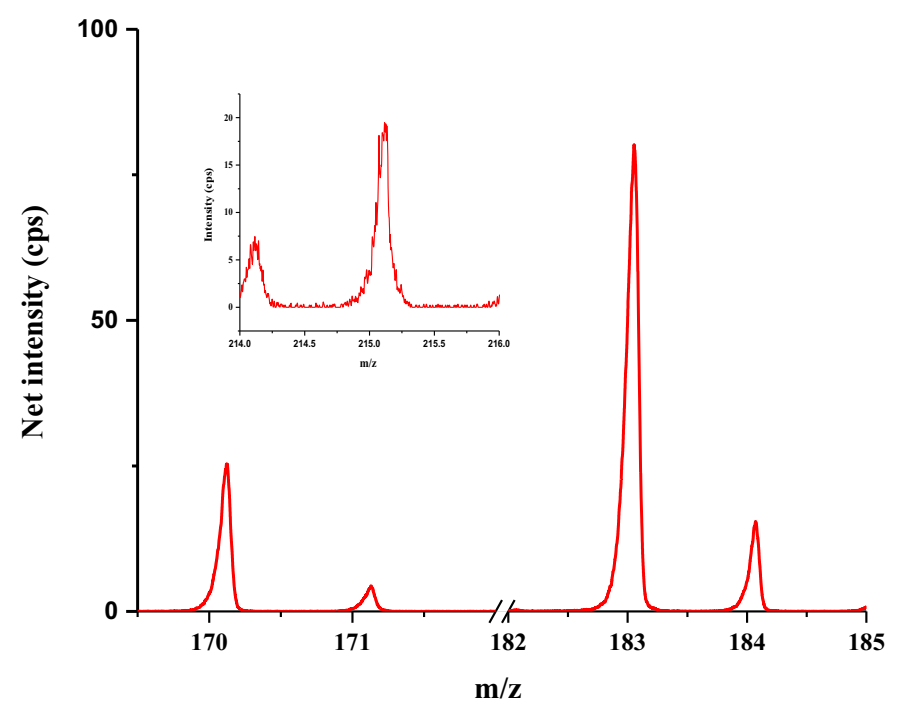

(a)
The other three samples showed an intense peak at $\mathrm{m} / \mathrm{z}$ 228.03. Fast switching experiments and previous studies dealing with 2,4,6-trinitrotoluene (TNT) and nitroglycerine (NG) confirmed this to be NG $[41,49,50]$. NG produces a characteristic signal at $m / z 46.01\left(\mathrm{NO}_{2}{ }^{+}\right)$at high $E / N$ values, whilst TNT does not; thus, a quick change in the $E / N$ from low (80 Td) to high $(180 \mathrm{Td})$ allows to assign this peak to NG.

Both Alliant powders show evidence of 2,4-DNT and also peaks at $m / z 170.10,215.08$ and 269.17, assigned to [DPA.H] $]^{+}$, [2-,4-NO2-DPA.H $]^{+}$and $[\mathrm{EC} . \mathrm{H}]^{+}$, respectively. Fast $E / N$ switching experiments confirm the identity of these species based on the presence or absence of fragment ions at different reduced electric fields. Fast switching experiments based on Fig. 1a, b, for both Alliant Red Dot and Unique powder, as shown in Fig. 5, confirmed the identity of $m / z 215.08$ to be the

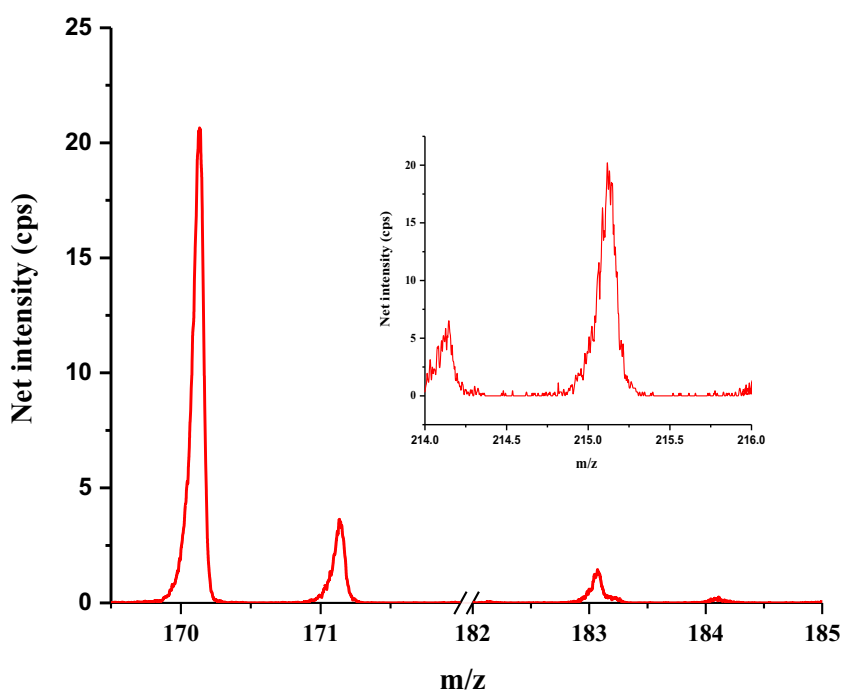

(b)

Figure 4. Mass spectra using water chemistry and reduced electric field of 140 Td for (a) IMR4198 and (b) Hodgdon BL- C[2] showing regions around $\mathrm{m} / \mathrm{z} 170$ and 215 and the different composition for both powders. (The insertion represents an expansion of the mass range around $m / z 215(\times 20))$ 


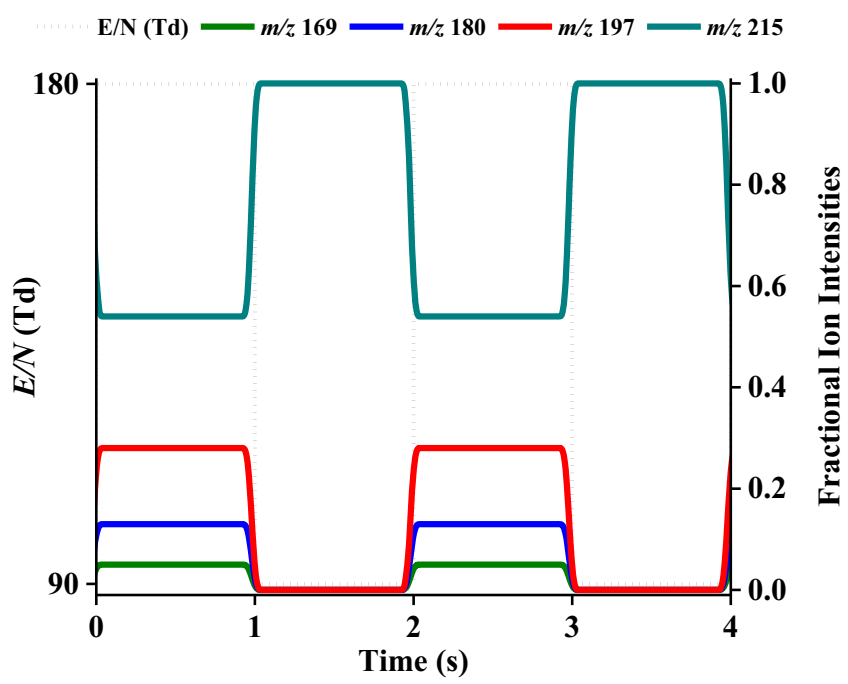

Figure 5. Changes in the fractional ion intensities averaged over each cycle using fast $E / N$ switching experiments at $1 \mathrm{~Hz}$ between 90 Td and 180 Td for Alliant Red Dot. The product ions showed are distinctive of 2- $\mathrm{NO}_{2}$-DPA. The dotted line represents the $E / N$ during each phase

2-nitrodiphenylamine isomer. The presence or absence of $\mathrm{m} / \mathrm{z}$ 197.07 and 198.08 would rule out one or another. Also, the presence of $\mathrm{m} / \mathrm{z} 180.06$ would confirm the existence of $2-\mathrm{NO}_{2}-$ DPA.

For the Hodgdon samples, only H322 did show evidences of 2,4-DNT, but BL- C[2] showed a signal at $\mathrm{m} / z$ 228.03, assigned again to NG based on fast switching experiments. Both Hodgdon samples showed clear signals at $\mathrm{m} / \mathrm{z} 170.10$ and 215.08. Fast switching experiments confirmed $\mathrm{m} / \mathrm{z} 215.08$ to be 2-nitrodiphenylamine for Hodgdon-BL- C[2]. However, in $\mathrm{O}_{2}{ }^{+}$ mode, no evidence for 2-nitrodiphenylamine was observed.

Both IMR samples showed a clear and intense peak for 2,4DNT, and peaks at $\mathrm{m} / \mathrm{z} 170.10,215.08,241.13$ and 269.17 were also observed. Fast switching experiments confirmed the nitrodiphenylamine to be a mixture of the 2- and 4-isomers.

As stated in the introduction, owing to the complex composition of smokeless powders, the presence of unidentified peaks was expected, the majority coming from the plasticizers used in the manufacturing process. This was confirmed by additional unidentified peaks for all the powders at $m / z 149.02$ (reported by Scherperel et al. as a dibutyl phthalate fragment) [29], 205.09 and 279.16 (the latter is assigned to be protonated dibutyl phthalate [DBP.H] ${ }^{+}$by Reese et al. [8] and Perez et al. [15]). It is evident that a more detailed study dealing with these is needed if a complete chemical analysis is required.

\section{Conclusions}

We have shown that direct injection soft chemical ionisationmass spectrometry, using both water and oxygen reagent gases, can analyse smokeless powder organic additives. This has been applied to their identification for commercial powders in their pre-detonation condition.
This method makes use of commercially available swabs and thermal desorption, allowing complete analysis of samples within $\sim 10 \mathrm{~s}$. For a series of the most common organic additives for smokeless powders, fragmentation patterns have been established and analytical figures of merit have been reported. Achieving the best LoDs for oxygen chemistry requires using lower reduced electric field values than those used for water chemistry. Oxygen chemistry has been tested to be less sensitive than water chemistry for the compounds of interest. Fragmentation has been shown to be very similar in terms of the observed ions and their identity for both reagent ions. For $\mathrm{H}_{3} \mathrm{O}^{+}$ and $\mathrm{O}_{2}{ }^{+}$, the most intense ions are usually coming from the non-dissociative channels.

Fast switching experiments aided in the identification and distinguish between isomers, based on the presence or absence of fragment ions at different reduced electric fields.

When applied to commercial samples, results have shown that the content of the organic additives investigated in this study changed between the samples, helping to differentiate among samples and manufacturers.

Future work will include extending the number of additives and plasticisers and commercial samples. Moreover, and also importantly, analysis of post-blast samples to ensure organic gunshot residues can be detected in a rapid, sensitive and selective way using this DI-SCIMS technology. Similar to recent studies [47], the potential use of a radiofrequency ion funnel drift tube to check for improvements in both sensitivity and selectivity is worthwhile to mention.

\section{Acknowledgements}

RGM is an early-stage researcher who acknowledges the support of the PIMMS Initial Training Network which in turn is supported by the European Commission's Seventh Framework Programme under Grant Agreement Number 287382.

\section{References}

1. Heramb, R. M.; McCord, B. R, The manufacture of smokeless powders and their forensic analysis: a brief review. Forensic Sci. Commun 2002, 4 (2)

2. Bender, E. C., Analysis of low explosives. In Forensic Investigation of Explosions, Taylor \& Francis Ltd., Bristol, PA: 1998

3. Schwoeble, A., Exline, D.L.: Current methods in forensic gunshot residue analysis. CRC Press (2000)

4. Chang, K.H., Jayaprakash, P.T., Yew, C.H., Abdullah, A.F.L.: Gunshot residue analysis and its evidential values: a review. Aust J Forensic Sci. 45(1), 3-23 (2013)

5. MacCrehan, W.A., Smith, K.D., Rowe, W.F.: Sampling protocols for the detection of smokeless powder residues using capillary electrophoresis. J. Forensic Sci. 43(1), 119-124 (1998)

6. Abrego, Z., Ugarte, A., Unceta, N., Fernández-Isla, A., Goicolea, M.A., Barrio, R.J.: Unambiguous characterization of gunshot residue particles using scanning laser ablation and inductively coupled plasma-mass spectrometry. Anal. Chem. 84(5), 2402-2409 (2012)

7. Dennis, D.-M.K., Williams, M.R., Sigman, M.E.: Assessing the evidentiary value of smokeless powder comparisons. Forensic Sci. Int. 259, 179-187 (2016) 
8. Reese, K.L., Jones, A.D., Smith, R.W.: Characterization of smokeless powders using multiplexed collision-induced dissociation mass spectrometry and chemometric procedures. Forensic Sci. Int. 272, 16-27 (2017)

9. Goudsmits, E., Sharples, G.P., Birkett, J.W.: Recent trends in organic gunshot residue analysis. TrAC Trends Anal. Chem. 74, 46-57 (2015)

10. Taudte, R.V., Beavis, A., Blanes, L., Cole, N., Doble, P., Roux, C.: Detection of gunshot residues using mass spectrometry. Biomed. Res. Int. 2014, 16 (2014)

11. Dalby, O., Butler, D., Birkett, J.W.: Analysis of gunshot residue and associated materials - a review. J. Forensic Sci. 55(4), 924-943 (2010)

12. Joshi, M., Rigsby, K., Almirall, J.R.: Analysis of the headspace composition of smokeless powders using GC-MS, GC- $\mu \mathrm{ECD}$ and ion mobility spectrometry. Forensic Sci. Int. 208(1-3), 29-36 (2011)

13. Meng, H., Caddy, B.: Gunshot residue analysis - a review. J. Forensic Sci. 42(4), 553-570 (1997)

14. Mach, M., Pallos, A., Jones, P.: Feasibility of gunshot residue detection via its organic constituents. Part I: analysis of smokeless powders by combined gas chromatography-chemical ionization mass spectrometry. J. Forensic Sci. 23(3), 433-445 (1978)

15. Perez, J.J., Watson, D.A., Levis, R.J.: Classification of gunshot residue using laser electrospray mass spectrometry and offline multivariate statistical analysis. Anal. Chem. 88(23), 11390-11398 (2016)

16. MacCrehan, W.A., Bedner, M.: Development of a smokeless powder reference material for propellant and explosives analysis. Forensic Sci. Int. 163(1-2), 119-124 (2006)

17. Cascio, O., Trettene, M., Bortolotti, F., Milana, G., Tagliaro, F.: Analysis of organic components of smokeless gunpowders: high-performance liquid chromatogaphy vs. micellar electrokinetic capillary chromatography. Electrophoresis. 25(10-11), 1543-1547 (2004)

18. Meng, H.-h., Caddy, B.: Detection of N,N'-diphenyl-N,N'-diethylurea (ethyl centralite) in gunshot residues using high-performance liquid chromatography with fluorescence detection. Analyst. 120(6), 1759-1762 (1995)

19. López-López, M., Bravo, J.C., García-Ruiz, C., Torre, M.: Diphenylamine and derivatives as predictors of gunpowder age by means of HPLC and statistical models. Talanta. 103, 214-220 (2013)

20. Laza, D., Nys, B., Kinder, J.D., Kirsch-De Mesmaeker, A., Moucheron, C.: Development of a quantitative LC-MS/MS method for the analysis of common propellant powder stabilizers in gunshot residue. J. Forensic Sci. 52(4), 842-850 (2007)

21. Wu, Z., Tong, Y., Yu, J., Zhang, X., Yang, C., Pan, C., Deng, X., Wen, Y., Xu, Y., The utilization of MS-MS method in detection of GSRs. J. Forensic Sci. 46 (3), 495-501 (2001)

22. Thomas, J.L., Lincoln, D., McCord, B.R.: Separation and detection of smokeless powder additives by ultra performance liquid chromatography with tandem mass spectrometry (UPLC/MS/MS). J. Forensic Sci. 58(3), 609-615 (2013)

23. López-López, M., Ferrando, J.L., García-Ruiz, C.: Comparative analysis of smokeless gunpowders by Fourier transform infrared and Raman spectroscopy. Anal. Chim. Acta. 717, 92-99 (2012)

24. Zeichner, A., Eldar, B., Glattstein, B., Koffman, A., Tamiri, T., Muller, D.: Vacuum collection of gunpowder residues from clothing worn by shooting suspects, and their analysis by GC/TEA, IMS, and GC/MS. J. Forensic Sci. 48(5), 961-972 (2003)

25. Cruces-Blanco, C., Gámiz-Gracia, L., García-Campaña, A.M.: Applications of capillary electrophoresis in forensic analytical chemistry. TrAC Trends Anal. Chem. 26(3), 215-226 (2007)

26. Bernal Morales, E., Revilla Vázquez, A.L.: Simultaneous determination of inorganic and organic gunshot residues by capillary electrophoresis. J. Chromatogr. A. 1061(2), 225-233 (2004)

27. West, C., Baron, G., Minet, J.J.: Detection of gunpowder stabilizers with ion mobility spectrometry. Forensic Sci. Int. 166(2-3), 91-101 (2007)

28. Joshi, M., Delgado, Y., Guerra, P., Lai, H., Almirall, J.R.: Detection of odor signatures of smokeless powders using solid phase microextraction coupled to an ion mobility spectrometer. Forensic Sci. Int. 188(1-3), 112118 (2009)

29. Scherperel, G., Reid, G.E., Waddell Smith, R.: Characterization of smokeless powders using nanoelectrospray ionization mass spectrometry (nESI-MS). Anal. Bioanal. Chem. 394(8), 2019-2028 (2009)

30. Wu, Z., Tong, Y., Yu, J., Zhang, X., Pan, C., Deng, X., Xu, Y., Wen, Y.: Detection of N,N [prime or minute]-diphenyl-N,N [prime or minute]dimethylurea (methyl centralite) in gunshot residues using MS-MS method. Analyst. 124(11), 1563-1567 (1999)
31. Tong, Y., Wu, Z., Yang, C., Yu, J., Zhang, X., Yang, S., Deng, X., Xu, Y., Wen, Y.: Determination of diphenylamine stabilizer and its nitrated derivatives in smokeless gunpowder using a tandem MS method. Analyst. 126(4), 480-484 (2001)

32. Perez, J.J., Flanigan, P.M., Brady, J.J., Levis, R.J.: Classification of smokeless powders using laser electrospray mass spectrometry and offline multivariate statistical analysis. Anal. Chem. 85(1), 296-302 (2013)

33. Zhao, M., Zhang, S., Yang, C., Xu, Y., Wen, Y., Sun, L., Zhang, X.: Desorption electrospray tandem MS (DESI-MSMS) analysis of methyl centralite and ethyl centralite as gunshot residues on skin and other surfaces. J. Forensic Sci. 53(4), 807-811 (2008)

34. Morelato, M., Beavis, A., Ogle, A., Doble, P., Kirkbride, P., Roux, C.: Screening of gunshot residues using desorption electrospray ionisationmass spectrometry (DESI-MS). Forensic Sci. Int. 217(1-3), 101-106 (2012)

35. Li, F., Tice, J., Musselman, B.D., Hall, A.B.: A method for rapid sampling and characterization of smokeless powder using sorbent-coated wire mesh and direct analysis in real time-mass spectrometry (DART-MS). Sci. Justice. 56(5), 321-328 (2016)

36. Mahoney, C.M., Gillen, G., Fahey, A.J.: Characterization of gunpowder samples using time-of-flight secondary ion mass spectrometry (TOFSIMS). Forensic Sci. Int. 158(1), 39-51 (2006)

37. Bueno, J., Sikirzhytski, V., Lednev, I.K.: Raman spectroscopic analysis of gunshot residue offering great potential for caliber differentiation. Anal. Chem. 84(10), 4334-4339 (2012)

38. Andrew, M., Ellis, C.A.M.: Proton transfer reaction mass spectrometry: principles and applications. $1^{\text {st }}$ Ed. Wiley (2014)

39. Biasioli, F., Yeretzian, C., Märk, T.D., Dewulf, J., Van Langenhove, H.: Direct-injection mass spectrometry adds the time dimension to (B) VOC analysis. TrAC Trends Anal. Chem. 30(7), 1003-1017 (2011)

40. Lindinger, W., Hirber, J., Paretzke, H.: An ion/molecule-reaction mass spectrometer used for on-line trace gas analysis. Int. J. Mass Spectrom. Ion Process. 129, 79-88 (1993)

41. González-Méndez, R., Reich, D.F., Mullock, S.J., Corlett, C.A., Mayhew, C.A.: Development and use of a thermal desorption unit and proton transfer reaction mass spectrometry for trace explosive detection: determination of the instrumental limits of detection and an investigation of memory effects. Int. J. Mass Spectrom. 385, 13-18 (2015)

42. Shen, C., Li, J., Han, H., Wang, H., Jiang, H., Chu, Y.: Triacetone triperoxide detection using low reduced-field proton transfer reaction mass spectrometer. Int. J. Mass Spectrom. 285(1-2), 100-103 (2009)

43. Mayhew, C.A., Sulzer, P., Petersson, F., Haidacher, S., Jordan, A., Märk, L., Watts, P., Märk, T.D.: Applications of proton transfer reaction timeof-flight mass spectrometry for the sensitive and rapid real-time detection of solid high explosives. Int. J. Mass Spectrom. 289(1), 58-63 (2010)

44. Jürschik, S., Sulzer, P., Petersson, F., Mayhew, C.A., Jordan, A., Agarwal, B., Haidacher, S., Seehauser, H., Becker, K., Märk, T.D.: Proton transfer reaction mass spectrometry for the sensitive and rapid real-time detection of solid high explosives in air and water. Anal. Bioanal. Chem. 398(7-8), 2813-2820 (2010)

45. Sulzer, P., Agarwal, B., Jürschik, S., Lanza, M., Jordan, A., Hartungen, E., Hanel, G., Märk, L., Märk, T.D., González-Méndez, R., Watts, P., Mayhew, C.A.: Applications of switching reagent ions in proton transfer reaction mass spectrometric instruments for the improved selectivity of explosive compounds. Int. J. Mass Spectrom. 354-355(0), 123-128 (2013)

46. Agarwal, B., González-Méndez, R., Lanza, M., Sulzer, P., Märk, T.D., Thomas, N., Mayhew, C.A.: Sensitivity and selectivity of switchable reagent ion soft chemical ionization mass spectrometry for the detection of picric acid. J. Phys. Chem. A. 118(37), 8229-8236 (2014)

47. González-Méndez, R., Watts, P., Olivenza-León, D., Reich, D.F., Mullock, S.J., Corlett, C.A., Cairns, S., Hickey, P., Brookes, M., Mayhew, C.A.: Enhancement of compound selectivity using a radio frequency ion-funnel proton transfer reaction mass spectrometer: improved specificity for explosive compounds. Anal. Chem. $88(21)$, 10624-10630 (2016)

48. González-Méndez, R.: Development and applications of proton transfer reaction-mass spectrometry for homeland security: trace detection of explosives. PhD. In: University Of Birmingham (2017)

49. Sulzer, P., Petersson, F., Agarwal, B., Becker, K.H., Jürschik, S., Märk, T.D., Perry, D., Watts, P., Mayhew, C.A.: Proton transfer reaction mass spectrometry and the unambiguous real-time detection of 2,4,6 trinitrotoluene. Anal. Chem. 84(9), 4161-4166 (2012) 
50. González-Méndez, R., Watts, P., Reich, D.F., Mullock, S.J., Cairns, S., Hickey, P., Brookes, M., Mayhew, C.A.: Use of rapid reduced electric field switching to enhance compound specificity for proton transfer reaction-mass spectrometry. Anal. Chem. 90(9), 5664-5670 (2018)

51. Eiceman, G.A., Karpas, Z., Hill Jr., H.H.: Ion mobility spectrometry. CRC press (2013)

52. Jordan, A., Haidacher, S., Hanel, G., Hartungen, E., Herbig, J., Märk, L., Schottkowsky, R., Seehauser, H., Sulzer, P., Märk, T.D.: An online ultrahigh sensitivity proton-transfer-reaction mass-spectrometer combined with switchable reagent ion capability (PTR + SRI - MS). Int. J. Mass Spectrom. 286(1), 32-38 (2009)
53. Harrison, A.G.: Chemical ionization mass spectrometry. CRC Press (1982)

54. Gross, J.H.: Mass spectrometry. A textbook. 2nd Ed. Springer (2011)

55. Gilbert-López, B., García-Reyes, J.F., Ortega-Barrales, P., Molina-Díaz, A., Fernández-Alba, A.R.: Analyses of pesticide residues in fruit-based baby food by liquid chromatography/electrospray ionization time-offlight mass spectrometry. Rapid Commun. Mass Spectrom. 21(13), 2059-2071 (2007)

56. The Smokeless Powders Database http://www.ilrc.ucf.edu/powders/ index.php. Accessed 08 Jan 2018 